\title{
APLIKASI PERSAMAAN DIFERENSIAL MODEL POPULASI LOGISTIK UNTUK MENGESTIMASI PENDUDUK DI KOTA BALIKPAPAN
}

\section{APPLICATION OF DIFFERENTIAL EQUATION OF LOGISTIC POPULATION MODEL TO ESTIMATE POPULATION IN BALIKPAPAN CITY}

\author{
Caecilia Dian Pratiwi ${ }^{\mathrm{a}}$ \\ ${ }^{a}$ Program Studi Pendidikan Matematika FKIP USD \\ Jl. Paingan, Krodan, Maguwoharjo Kec.Depok, Kabupaten Sleman, Daerah Istimewa \\ Yogyakarta, caeciliadian3@gmail.com
}

\begin{abstract}
ABSTRAK
Proyeksi jumlah penduduk merupakan sebuah perkiraan penduduk di masa depan berdasarkan kecenderungan saat ini dan masa lalu. Model populasi logistik adalah suatu model yang berasumsi bahwa pada waktu tertentu populasi akan mencapai titik kesetimbangan atau titik equilibrium. Penelitian ini bertujuan untuk mengetahui estimasi jumlah penduduk Kota Balikpapan pada $t=10$ atau pada tahun 2025 dengan menggunakan model pertumbuhan penduduk yaitu model logistik. Berdasarkan data yang diperoleh dari BPS (Badan Pusat Statistik) Kota Balikpapan pada tahun 2015 sampai dengan tahun 2018, dapat diasumsikan bahwa batas tampung $(\mathrm{K})=809967$. Hasil dari penelitian ini menunjukkan bahwa model yang akurat untuk dipakai dalam mengetahui estimasi jumlah penduduk Kota Balikpapan yaitu model dengan $\mathrm{k}=0,4795214107, \mathrm{P}(\mathrm{t})=$ 809967

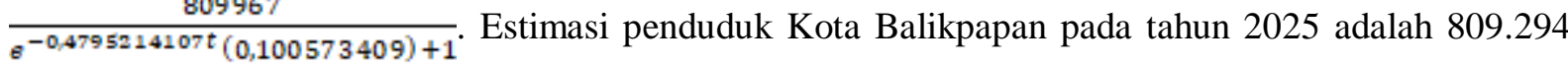
jiwa.
\end{abstract}

Kata Kunci: Model Logistik, Proyeksi Penduduk, Persamaan Diferensial.

\section{ABSTRACT}

The population projection is an estimate of the population in the future based on current and past trends. The logistic population model is a model that assumes that at a certain time the population will reach an equilibrium or equilibrium point. This study aims to determine the estimated population of Balikpapan City at $t=10$ or in 2025 by using a population growth model that is logistic. Based on data obtained from the BPS (Statistics Indonesia) of the City of Balikpapan in 2015 to 2018, it can be assumed that the limit $(K)=$ 809967. The results of this study indicate that an accurate model to be used in knowing the estimated population of the City of Balikpapan i.e. the model with $k=0.4795214107, \mathrm{P}(\mathrm{t})=$ $\frac{809967}{\mathrm{a}^{-0,479514107 t}(0,100573409)+1}$. The estimated population of Balikpapan City in 2025 is 809,294 inhabitants.

Keywords: Logistics Models, Population Projection, Differential Equations 


\section{Pendahuluan}

Salah satu permasalahan yang sering terjadi di negara-negara berkembang salah satunya adalah permasalahan penduduk. Seiring dengan bertambahnya populasi penduduk, maka akan semakin banyak permasalahan yang terjadi diantaranya permasalahan di bidang perekonomian, permasalahan ketenagakerjaan yang menyebabkan semakin banyaknya pengangguran, permasalahan pembangunan, standar hidup serta kriminalitas akan semakin meningkat. Hal ini sejalan dengan apa yang disampaikan oleh Sunaryanto (Indraswari, 2017: 1) bahwa sebenarnya permasalahan kependudukan telah menjadi masalah penting bagi pemerintah dan para pakar kependudukan di Indonesia. Berdasarkan hasil World Population Review, Indonesia menempati posisi keempat dengan jumlah penduduk paling banyak yakni 268.369.114 juta jiwa setelah negara China, India, dan United States. Oleh sebab itu, seiring dengan bertambahnya populasi penduduk penting bagi pemerintah maupun para pakar terkait untuk melakukan perencanaan-perencanaan jika pada beberapa tahun yang akan mendatang terjadi ledakan populasi penduduk sehingga dapat menimbulkan permasalahan.

Berdasarkan permasalahan tersebut, peneliti mengkaji berapa banyak populasi penduduk di salah satu daerah di Indonesia yakni Kota Balikpapan, Balikpapan merupakan salah kota yang terletak di wilayah Kalimantan Timur. Tepatnya berada di koordinat $1^{\circ} 8^{\prime} 56^{\prime \prime} \mathrm{S} 116^{\circ} 54^{\prime} 11^{\prime \prime}$ E. Luas wilayah yang dimiliki adalah 503,3 $\mathrm{km}^{2}$ atau 50.330,57 hektar, dengan jumlah penduduk pada tahun 2018 menurut Badan Pusat Statistik Kota Balikpapan (BPS Kota Balikpapan) adalah 645.727 jiwa. Balikpapan juga dikenal dengan sebutan kota minyak. Hal ini dikarenakan Balikpapan merupakan salah satu kota penghasil minyak terbesar di Indonesia dengan $85 \%$ bentuk muka bumi dari kota Balikpapan adalah wilayah perbukitan. Adapun batas wilayah administratif kota ini, sebagai berikut: (1) Sebelah Utara berbatasan dengan Kabupaten Kutai Kartanegara; (2) Sebelah Selatan berbatasan dengan Selat Makassar; (3) Sebelah Barat berbatasan dengan Kabupaten Penajam Paser Utara; (4) Sebelah Timur berbatasan dengan Selat Makassar. Berdasarkan wilayah dan dengan kepadatan penduduk di Kota 
Balikpapan ini menyebabkan tidak meratanya penduduk yang tersebar di masing-masing kecamatan. Sejalan dengan kondisi dari Kota Balikpapan tersebut, Pemerintah Republik Indonesia telah mencanangkan pemindahan Ibukota Negara yang baru dan bertempat di Kalimantan Timur yakni di Kutai Kartanegara. Mengingat hal ini, Kota Balikpapan sebagai salah satu Kota yang letaknya tidak jauh dari Ibukota yang baru pasti akan mendapatkan dampak dari pemindahan tersebut. Salah satu dampak yang akan terasa adalah terjadinya ledakan penduduk (meningkatnya populasi penduduk) dimana dengan populasi penduduk yang semakin meningkat tentunya juga tidak terlepas dari meningkatnya permasalahan seperti kriminalitas, ketenagakerjaan, standar hidup baik dibidang kesehatan maupun Pendidikan.

Berdasarkan permasalahan tersebut Siregar (Nuraini, 2018: 402) mengatakan bahwa permasalahan yang dapat dimodelkan dalam persamaan diferensial salah satunya adalah permasalahan dalam bidang demografi. Oleh sebab itu salah satu langkah yang diambil oleh peneliti adalah dengan mengkaji populasi penduduk Kota Balikpapan menggunakan model matematika. Hal ini sejalan dengan apa yang disampaikan oleh Hala (2016: 81) ia mengatakan bahwa salah satu cara untuk mengurangi dampak negatif dari pertumbuhan suatu populasi adalah dengan menggunakan proyeksi pertumbuhan dari populasi tersebut. Salah satu model pertumbuhan populasi yang dapat digunakan adalah model populasi logistik dimana dari waktu ke waktu populasi ini terus bergantung pada waktu. Adapun berdasarkan permasalahan di atas, peneliti mengkaji rumusan masalah yang sesuai dengan penelitian ini yaitu:

1. Bagaimana model Logistik pertumbuhan penduduk Kota Balikpapan?

2. Berapa estimasi jumlah penduduk Kota Balikpapan pada tahun 2025 dengan menggunakan model pertumbuhan penduduk yaitu model logistik?

Berdasarkan rumusan masalah yang telah dipaparkan oleh peneliti, maka adapun tujuan dari penelitian ini antara lain:

1. Untuk mengetahui terkait model Logistik dari pertumbuhan penduduk Kota Balikpapan.

2. Untuk mengetahui estimasi jumlah penduduk Kota Balikpapan pada tahun 2025 dengan menggunakan model 
pertumbuhan penduduk yaitu model logistik.

\subsection{Populasi Penduduk}

Menurut KBBI (2016) populasi merupakan sekelompok orang, benda, atau hal yang menjadi sumber pengambilan sampel atau suatu kumpulan yang memenuhi syarat tertentu yang berkaitan dengan masalah penelitian. Menurut KBBI (2016) penduduk merupakan orang yang mendiami suatu tempat (kampung, negeri, pulai dan sebagainya). Berdasarkan hal tersebut dapat disimpulkan bahwa populasi penduduk merupakan sekelompok orang yang mendiami suatu wilayah tertentu yang menjadi sumber pengambilan sampel terkait penelitian.

\subsection{Laju Pertumbuhan Penduduk}

Masalah kependudukan selalu menjadi momok permasalahan bagi setiap daerah maupun setiap negara. Meningkatnya populasi penduduk dari tahun ke tahun menyebabkan kepadatan penduduk juga semakin meningkat. Hal terkait pertumbuhan penduduk juga disampaikan oleh Keuangan (2015: 17), yang memaparkan bahwa laju pertumbuhan penduduk adalah pertumbuhan jumlah penduduk di suatu wilayah tertentu setiap tahunnya yang kegunaannya adalah untuk memprediksi jumlah penduduk di suatu wilayah di masa yang akan datang. Oleh sebab itu, laju pertumbuhan yang tinggi merupakan permasalahan yang cukup genting dan sedang dihadapi oleh negaranegara berkembang di dunia, khususnya negara-negara yang berpenduduk besar dan padat atau negara berkembang. Hal ini disebabkan oleh keterbatasan data dasar yang diperoleh mengenai jumlah kelahiran, sehingga diperlukan berbagai upaya yang berkesinambungan untuk menurunkan laju pertumbuhan penduduk. Indonesia syang merupakan salah satu negara yang sedang berkembang dengan penduduk terbesar nomor empat di dunia juga sedang menghadapi persoalan yang serupa. Berdasarkan hal tersebut, terdapat beberapa aspek penting yang dipertimbangkan terkait masalah kependudukan yang harus diperhatikan agar masalah kependudukan tidak terus menerus menjadi momok permasalahan bagi sebuah negara maupun sebuah daerah.

\subsection{Proyeksi Jumlah Penduduk}

Bappenas (2006) mengatakan bahwa proyeksi jumlah penduduk adalah suatu perkiraan jumlah penduduk 
berdasarkan metode tertentu dengan asumsi - asumsi kelahiran, kematian dan migrasi. Hal ini sejalan berdasarkan KBBI (2016) menyatakan bahwa "perkiraan" adalah sesuatu yang diperkirakan berdasarkan perhitungan. Sedangkan "proyeksi" menurut KBBI (2016) menyatakan bahwa proyeksi mengandung pengertian terkait perkiraan tentang masa yang akan dating dengan menggunakan data yang ada sekarang. Berdasarkan hal tersebut dapat ditarik kesimpulan bahwa proyeksi penduduk dapat dikatakan sebagai perkiraan penduduk di masa depan berdasarkan kecenderungan saat ini dan masa lalu.

\subsection{Model Matematika}

Pemodelan matematika merupakan suatu cara untuk merepresentasikan persoalan kompleks ke dalam bentuk matematika, hal ini di paparkan oleh Ndii (2018: 1). Berikutnya, model matematika merupakan abstraksi, penyederhanaan dan konstruksi matematika terkait bagian dari kenyataan dan didesain untuk tujuan khusus. Model matematika yang biasanya dapat kita temui dapat berupa persamaan atau system persamaan, dimana persamaan ini diharapkan dapat merepresentasikan hal-hal yang penting dan mengabaikan hal yang dianggap kurang penting. Sejalan dengan pendapat tersebut Iswanto (2012: 2) menyatakan bahwa pemodelan matematika di desain untuk memberian deskripsi system secara fisik dengan persamaan atau yang lebih umum dengan logika dan struktur perhitungan komputer. Hal ini dikarenakan model matematika merupakan salah satu teknik merepresentasikan suatu permasalahan kompleks yang sedang diamati maka diharapkan model matematika yang diformulasi harus dapat menjelaskan situasi kompleks yang sedang diamati.

\subsection{Model Pertumbuhan Eksponensial}

Ketika melakukan estimasi populasi penduduk dengan laju pertumbuhan yang konstan, dapat digunakan model pertumbuhan eksponensial. Hal yang serupa diungkapkan oleh Nuraeni (2017: 11) mengatakan bahwa model pertumbuhan eksponensial digunakan dengan asumsi bahwa populasi bertambah dengan laju pertumbuhan populasi yang sebanding dengan besarnya populasi, dimana $P(t)$ adalah jumlah populasi saat $t$ adalah waktu dengan $k$ adalah laju pertumbuhan populasi. Berdasarkan apa yang 
disampaikan tersebut maka model populasi eksponensial dapat dinyatakan sebagai berikut:

$\frac{d P}{d t}=k P(t)$

Berdasarkan hal tersebut untuk menentukan solusi eksplisit dapat dengan menggunakan metode separasi variabel sehingga diperoleh persamaan berikut:

$P(t)=P_{0} e^{k t}$

Pada penelitian ini, peneliti menggunakan model pertumbuhan logistik. Hal ini dikarenakan, ketika menggunakan model eksponensial maupun model logistik keduanya samasama memiliki galat atau eror terkecil sehingga keduanya sama-sama mendekati pendugaan data jumlah penduduk Kota Balikpapan pada tahun 2015-2018. Namun, dari kedua model tersebut model logistik dapat lebih akurat untuk melakukan estimasi populasi penduduk di beberapa tahun yang akan datang. Hal ini sejalan dengan apa yang disampaikan oleh Kurniawan (2017: 139) yang menyatakan bahwa model logistik adalah model yang terbaik untuk pendugaan jumlah penduduk yang akan datang.

\subsection{Model Pertumbuhan Logistik}

Pada pelaksanaannya, model pertumbuhan logistik dianggap memiliki akurasi yang sangat tinggi, hal ini dikarenakan model ini memiliki galat yang paling kecil. Menurut Sulaiman (2016: 689-690) model logistik disusun berdasarkan asumsi-asumsi berikut ini:

1. Populasi akan mencapai titik kesetimbangan (titik equilibrium) dengan lingkungan, sehingga memiliki sebaran umur stabil.

2. Populasi memiliki laju pertumbuhan yang secara berangsur-angsur menurun secara tetap dengan konstanta $r$.

3. Pengaruh dari $r$ terhadap peningkatan kerapatan karena tumbuhnya populasi merupakan respons seketika itu juga dan tidak terdapat penundaan atau senjang waktu.

4. Sepanjang waktu pertumbuhan keadaan lingkungan tidak berubah.

5. Pengaruh kerapatan adalah sama terhadap semua tingkat umur populasi.

6. Peluang untuk berkembang biak tidak dipengaruhi oleh kerapatan.

Berdasarkan hal tersebut, jika kita memiliki laju pertumbuhan populasi yang biasa dikenal dengan persamaan diferensial logistik seperti berikut ini: 


$$
\frac{d P}{d t}=k P\left(1-\frac{P}{K}\right)
$$

Berdasarkan persamaan (1) maka persamaan tersebut dapat diselesaikan secara eksplisit dengan mencari solusi umum persamaan logistik dengan menggunakan langkah-langkah sebagai berikut:

$$
\begin{aligned}
& \frac{d P}{d t}=k P\left(1-\frac{P}{K}\right), \\
& \frac{d P}{P\left(1-\frac{P}{K}\right)}=k d t \\
& \frac{d P}{P\left(1-\frac{P}{K}\right)}=\int k d t, \\
& \int \frac{d P}{P-\frac{P^{2}}{K}}=\int k d t_{p} \\
& \int \frac{K d P}{K P-P^{2}}=\int k d t \\
& \ln P-\ln (K-P)=k t+c_{\nu} \\
& \ln \left(\frac{P}{K-P}\right)=k t+c_{v} \\
& \frac{P}{K-P}=e^{k t+c} \text {, } \\
& P=e^{k t+\epsilon}(K-P) \text {, } \\
& P=K e^{k t+c}-P e^{k t+c}, \\
& P+P e^{k t+c}=K e^{k t+c}{ }_{,} \\
& P\left(1+e^{k t+\epsilon}\right)=K e^{k t+\epsilon}, \\
& P(t)=\frac{K e^{k t+c}}{1+e^{k t+c}}
\end{aligned}
$$

Berdasarkan persamaan (2) yang telah diperoleh, ketika diberikan nilai $t$ sebagai nilai awal $t=0$

$$
\begin{aligned}
& P(t)=\frac{K e^{k t+\ln \left(\frac{P_{0}}{K-P_{0}}\right)}}{1+e^{k t+\ln \left(\frac{P_{0}}{K-P_{0}}\right)}} \\
& P(t)=\frac{K e^{k t\left(\frac{P_{0}}{K-P_{0}}\right)}}{1+e^{k t\left(\frac{P_{0}}{K-P_{0}}\right)^{r}}} \\
& P(t)=\frac{\frac{K e^{k t} P_{0}}{K-P_{0}}}{\frac{K-P_{0}+e^{k t} P_{0}}{K-P_{\mathrm{n}}}} \\
& P(t)=\frac{K e^{k t} P_{0}}{K-P_{0}+e^{k t} P_{0}{ }^{g}} \\
& P(t)=\frac{K P_{0}}{\left(K-P_{\mathrm{n}}+e^{k t} P_{\mathrm{n}}\right) e^{-k t^{n}}} \\
& P(t)=\frac{K P_{0}}{\left(K e^{-k t}-P_{\mathrm{n}} e^{k t}+P_{\mathrm{n}}\right)^{y}} \\
& P(t)=\frac{K P_{0}}{\left(\frac{K}{P_{0}} e^{-k t}-e^{-k t}+1\right)^{n}} \\
& P(t)=\frac{K}{e^{-k t}\left(\frac{K}{P_{0}}-1\right)+1}
\end{aligned}
$$

Nilai $K$ diperoleh ketika $t \rightarrow \infty$ hal ini berarti nilai $K$ adalah populasi terbanyak ketika $t \rightarrow \infty$. Dengan demikian $N_{\max }=\lim _{t \rightarrow \infty} N=K=\frac{a}{b}$

Berikutnya, dengan melakukan substitusi nilai $K=\frac{a}{b}$ ke persamaan (3) diperoleh $K$ sebagai berikut:

$$
K=\frac{P_{1}\left(P_{1} P_{0}-2 P_{0} P_{2}+P_{1} P_{2}\right)}{P_{1}{ }^{2}-P_{\mathrm{n}} P_{2}}
$$

Berikut ini disajikan keterangan yang dapat membantu pembaca makalah ini sebagai berikut: 
Keterangan:

$K \quad$ : Kapasitas penduduk di suatu daerah

$P(t) \quad$ : Populasi penduduk pada saat waktu $t$

$P_{n} \quad$ : Populasi penduduk pada saat waktu $n$, dimana $n=1,2,3$

$k \quad$ : laju pertumbuhan penduduk

$t \quad$ : waktu

\section{Metode Penelitian}

Penelitian yang digunakan pada penelitian ini adalah penelitian jenis kajian pustaka. Adapun langkah-langkah penelitian kajian pustaka yang dilakukan adalah sebagai berikut:

1. Mempelajari definisi serta teoremateorema yang menjadi landasan dari penelitian ini.

2. Melakukan kajian solusi analitik untuk kasus model logistik serta melakukan pemodelan pertumbuhan penduduk Kota Balikpapan dengan menggunakan model tersebut.

3. Melakukan proyeksi jumlah penduduk Kota Balikpapan pada beberapa tahun yang akan datang dengan menggunakan model logistik.

Permasalahan yang akan peneliti kaji adalah bagaimana model matematika dan estimasi penduduk Kota Balikpapan. Berdasarkan hal tersebut metode yang digunakan oleh peneliti dalam penelitian ini adalah penelitian kajian pustaka. Metode ini bertujuan untuk memahami sebuah permasalahan terkait fenomena dan hal-hal yang berhubungan di dunia sosial yang terjadi saat sekarang.

\section{Hasil dan Pembahasan}

Berdasarkan data yang diperoleh dari Badan Pusat Statistik Kota Balikpapan pada tahun 2015 sampai dengan tahun 2018 dapat dilihat pada tabel data jumlah penduduk Kota Balikpapan seperti yang ada pada tabel 3.2 berikut:

Tabel 1. Data Jumlah Penduduk Kota

Balikpapan Tahun 2015-2018

\begin{tabular}{cccc}
\hline No. & Tahun & $\begin{array}{c}\text { Jumlah } \\
\text { Penduduk }\end{array}$ & Sumber \\
\hline 1. & 2015 & 735950 & Sumber: \\
2. & 2016 & 762492 & BPS Kota \\
3. & 2017 & 779905 & Balikpapan \\
\hline 4. & 2018 & 645727 & \\
\hline
\end{tabular}

Dengan menggunakan perhitungan seperti berikut:

$K=\frac{P_{1}\left(P_{1} P_{0}-2 P_{0} P_{2}+P_{1} P_{2}\right)}{P_{1}^{2}-P_{\mathrm{n}} P_{2}}$

Sehingga diperoleh nilai $K=809967$

Langkah berikutnya, menentukan nilai $k$ untuk masing-masing $t$ dengan melakukan substitusi ke persamaan (3) sehingga diperoleh:

Ketika $\mathrm{t}=1, P_{1}=762492$ 


$$
\begin{aligned}
& P(t)=\frac{K}{e^{-k t}\left(\frac{K}{P_{0}}-1\right)+1} \\
& P_{1}=\frac{K}{e^{-k t}\left(\frac{K}{P_{0}}-1\right)+1} \\
& 762492=\frac{809967}{e^{-k \cdot 1}\left(\frac{809967}{735950}-1\right)+1} \\
& 762492=\frac{809967}{e^{-k}(0,100573409)+1} \\
& 762492\left(e^{-k}(0,100573409)+1\right)=809967 \\
& \frac{0,62262948}{0,100573409}=e^{-k} \\
& 6,190821393=e^{-k} \\
& \ln 6,190821393=-k \\
& 1,823067775=-k \\
& -1,823067775=k
\end{aligned}
$$

Sehingga diperoleh $k$ ketika $\mathrm{t}=1$, $P_{1}=762492$ adalah $-1,823067775$

Ketika $\mathrm{t}=2, P_{2}=779905$

$P(t)=\frac{K}{e^{-k t}\left(\frac{K}{P_{0}}-1\right)+1}$

$P_{2}=\frac{K}{e^{-k t}\left(\frac{K}{P_{0}}-1\right)+1}$

$779905=\frac{809967}{e^{-2 k}\left(\frac{809967}{735950}-1\right)+1}$

$779905=\frac{809967}{e^{-2 k}(0,100573409)+1}$

$779905\left(e^{-2 k}(0,100573409)+1\right)=809967$

$\frac{0,03854572031}{0,100573409}=e^{-2 k}$

$0,3832595583=e^{-2 k}$ $\ln 0,3832595583=-2 k$

$-0,9590428214=-2 k$

$0,4795214107=k$

Sehingga diperoleh $k$ ketika $\mathrm{t}=2$,

$P_{2}=779905$ adalah 0,4795214107

Ketika $\mathrm{t}=3, P_{3}=645727$

$$
\begin{aligned}
& P(t)=\frac{K}{e^{-k t}\left(\frac{K}{P_{0}}-1\right)+1} \\
& P_{3}=\frac{K}{e^{-k t}\left(\frac{K}{P_{0}}-1\right)+1}
\end{aligned}
$$$$
645727=\frac{809967}{e^{-3 k}\left(\frac{809967}{735950}-1\right)+1}
$$$$
645727=\frac{809967}{e^{-3 k}(0,100573409)+1}
$$

$645727\left(e^{-3 k}(0,100573409)+1\right)=809967$

$\frac{0,2543489741}{0,100573409}=e^{-3 k}$

$2,528988295=e^{-3 k}$

$\ln 2,528988295=-3 k$

$0,9278193394=-3 k$

$-0,3092731131=k$

Sehingga diperoleh $k$ ketika $\mathrm{t}=3$, $P_{3}=645727$ adalah $-0,3092731131$

Selanjutnya, setelah mendapatkan nilai $k$ dari masing-masing $t$ maka diperoleh beberapa model logistik yang akan digunakan dan kemudian dipilih untuk melakukan pendugaan jumlah penduduk Kota Balikpapan pada tahun 2015 sampai tahun 2018. Berikut ini adalah hasil dari 
model logistik diantaranya sebagai berikut:

\section{Model Logistik I}

Untuk memperoleh model logistik ini, langkah yang dilakukan adalah dengan melakukan substitusi nilai $k=-1,823067775 ; \quad P_{0}=735950 ;$ serta $K=809967$ yakni ke persamaan (3) sehingga diperoleh hasil sebagai berikut:

$P(t)=\frac{K}{e^{-k t}\left(\frac{K}{P_{0}}-1\right)+1}$

$P(t)=\frac{809967}{e^{-(-1,823067775) t}\left(\frac{809967}{735950}-1\right)+1}$

$P(t)=\frac{809967}{e^{1,823067775 t}(0,100573409)+1}$

Maka model logistik I yang diperoleh adalah:

$$
P(t)=\frac{809967}{e^{1,823067775 t}(0,100573409)+1}
$$

2. Model Logistik II

Untuk memperoleh model logistik ini, langkah yang dilakukan adalah dengan melakukan substitusi nilai $k=0,4795214107 ; \quad P_{0}=735950 ;$ serta $\quad K=809967 \quad$ yakni ke persamaan (3) sehingga diperoleh hasil sebagai berikut:

$$
P(t)=\frac{K}{e^{-k t}\left(\frac{K}{P_{0}}-1\right)+1}
$$

$$
\begin{aligned}
& P(t)=\frac{809967}{e^{-(0,4795214107) t}\left(\frac{809967}{735950}-1\right)+1} \\
& P(t)=\frac{809967}{e^{-0,4795214107 t}(0,100573409)+1}
\end{aligned}
$$

Maka model logistik II yang diperoleh adalah:

$$
P(t)=\frac{809967}{e^{-0,4795214107 t}(0,100573409)+1}
$$

3. Model Logistik III

Untuk memperoleh model logistik ini, langkah yang dilakukan adalah dengan melakukan substitusi nilai $k=-0,3092731131 ; \quad P_{0}=735950$; serta $K=809967$ yakni ke persamaan (3) sehingga diperoleh hasil sebagai berikut:

$$
P(t)=\frac{K}{e^{-k t}\left(\frac{K}{P_{0}}-1\right)+1}
$$

$$
P(t)=\frac{809967}{e^{-(-0,3092731131) t}\left(\frac{809967}{735950}-1\right)+1}
$$

$P(t)=\frac{809967}{e^{0,3092731131 t}(0,100573409)+1}$

Maka model logistik III yang diperoleh adalah:

$P(t)=\frac{809967}{e^{0,3092731131 t}(0,100573409)+1}$ 
Model Logistik tersebut kemudian disubstitusi untuk mendapatkan hasil yang kemudian akan dibandingkan dengan data jumlah penduduk Kota Balikpapan pada tahun 2015 hingga tahun 2018 seperti berikut ini:

Tabel 2. Model Logistik

\begin{tabular}{ccccc}
\hline Tahun & $\mathrm{t}$ & Model I & Model II & Model III \\
\hline 2015 & 0 & 735949 & 735950 & 735950 \\
2016 & 1 & 499168 & 762492 & 712357 \\
2017 & 2 & 166845 & 779905 & 682545 \\
2018 & 3 & 32576.9 & 791089 & 645727
\end{tabular}

Berdasarkan tabel 2 di atas, peneliti kemudian memilih model terbaik yang memiliki error paling kecil dan memiliki hasil yang cukup dekat dengan data jumlah penduduk Kota Balikpapan. Berikut ini peneliti menyajikan model logistik disertai dengan error dari masingmasing model tersebut, sebagai berikut:

Tabel 3. Model Logistik disertai dengan Error Tiap Model

\begin{tabular}{cccccc}
\hline $\begin{array}{c}\text { Model } \\
\text { I }\end{array}$ & $\begin{array}{c}\text { Model } \\
\text { II }\end{array}$ & $\begin{array}{c}\text { Model } \\
\text { III }\end{array}$ & $\begin{array}{c}\text { Eror } \\
\text { Model } \\
\text { I }\end{array}$ & $\begin{array}{c}\text { Eror } \\
\text { Model } \\
\text { II }\end{array}$ & $\begin{array}{c}\text { Eror } \\
\text { Model } \\
\text { III }\end{array}$ \\
\hline 7359 & 7359 & 7359 & 0 & 0 & 0 \\
4991 & 7624 & 7123 & 6933 & 0 & 2513 \\
1668 & 7799 & 6825 & 3758 & 0 & 9479 \\
325 & 7910 & 6457 & 3759 & 2113 & 0 \\
\hline
\end{tabular}

Berdasarkan model dan error yang diperoleh kemudian peneliti membandingkan hasil penghitungan dari masing-masing model dengan data jumlah penduduk Kota Balikpapan pada tahun 2015 hingga tahun 2018 yakni sebagai berikut:

Tabel 4. Model Logistik dengan Data Jumlah Penduduk Kota Balikpapan

\begin{tabular}{|c|c|c|c|c|}
\hline \multirow[b]{2}{*}{ Thn } & Jumlah & \multicolumn{3}{|c|}{ Model Logistik } \\
\hline & $\begin{array}{l}\text { (BPS } \\
\text { Kota } \\
\text { Bpn) } \\
\end{array}$ & I & II & III \\
\hline 2015 & 735950 & 73595 & 73595 & 73595 \\
\hline 2016 & 762492 & 49916 & 76249 & 71235 \\
\hline 2017 & 779905 & 16684 & 77990 & 68254 \\
\hline 2018 & 645727 & 32577 & 79108 & 64572 \\
\hline
\end{tabular}

Berdasarkan tabel di atas, dapat dilihat bahwa ada model yang mengalami peningkatan maupun penurunan. Sehingga dari ketiga model yang dimiliki, model II merupakan model yang hasilnya benarbenar mendekati data jumlah penduduk Kota Balikpapan pada tahun 2015 sampai dengan tahun 2018. Hal tersebut juga diperkuat dengan nilai eror yang dimiliki yakni bahwa hasil penghitungan dari model II mendekati data jumlah penduduk Kota Balikpapan walaupun di tahun terakhir eror yang dimiliki semakin besar. Berbeda dengan model II, model ke- III justru memiliki eror yang kecil pada tahun terakhir, namun pada tahun kedua dan ketiga terjadi eror yang cukup besar. Untuk dapat mengetahui terjadinya peningkatan maupun penurunan maka 
peneliti akan menampilkan dalam bentuk grafik pada Gambar 1. sebagai berikut:

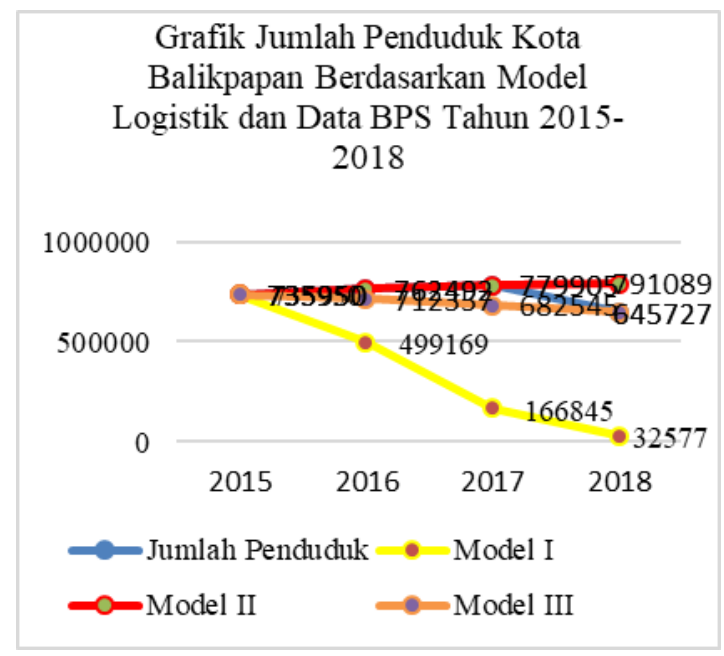

Gambar 1. Grafik Jumlah Penduduk Kota Balikpapan Berdasarkan Model Logistik dan Data BPS Tahun 2015-2018

Oleh sebab itu, berdasarkan Tabel 4 dan Gambar 1 serta dengan pertimbangan hasil penghitungan model II lebih mendekati data jumlah penduduk Kota Balikpapan dan berdasarkan eror yang dimiliki maka pada kasus ini peneliti mengambil model II sebagai model logistik yang digunakan.

Berikutnya, untuk mengetahui estimasi jumlah penduduk Kota Balikpapan ketika $t=10$ tahun yang akan mendatang, dengan menggunakan model logistik II diperoleh penghitungan sebagai berikut:

Ketika $t=10$

$P(t)=\frac{809967}{e^{-0,4795214107 t}(0,100573409)+1}$

$$
P(t)=\frac{809967}{e^{-0,4795214107(10)}(0,100573409)+1}
$$

$$
\begin{gathered}
P(t)=\frac{809967}{e^{-4,795214107}(0,100573409)+1} \\
P(t)=\frac{809967}{e^{-4,795214107}(0,100573409)+1} \\
P(t)=809294
\end{gathered}
$$

Maka, jumlah populasi penduduk Kota Balikpapan saat $t=10$ adalah 809294

\section{Kesimpulan}

Berdasarkan hasil penelitian yang telah dilakukan, maka dapat disimpulkan bahwa:

1. Berdasarkan perhitungan menggunakan model populasi logistik yang telah dilakukan diperoleh 3 macam model sesuai dengan nilai $k$ yang berbedabeda pada setiap tahunnya. Adapun ketiga model yang diperoleh sebagai berikut:

Model Logistik I:

$$
P(t)=\frac{809967}{e^{1,823067775 t}(0,100573409)+1}
$$

Model Logistik II:

$P(t)=\frac{809967}{e^{-0,4795214107 t}(0,100573409)+1}$

Model Logistik III:

$$
P(t)=\frac{809967}{e^{0,3092731131 t}(0,100573409)+1}
$$


Berdasarkan ketiga model di atas, model eksponensial II adalah model terbaik dan efektif yang dapat digunakan untuk melakukan prediksi penduduk Kota Balikpapan pada tahun 2025 atau ketika $t=10$.

2. Berdasarkan perhitungan yang dilakukan dengan menggunakan model logistik II maka diperoleh estimasi jumlah penduduk Kota Balikpapan ketika $t=10$ yakni pada tahun 2025 adalah sebanyak 809.294 jiwa.

\section{Daftar Pustaka}

Badan Perencanaan Pembangunan nasional (Bappenas), 2006. Proyeksi penduduk indonesia 2000-2025. Indonesia. Badan Perencanaan Pembangunan Nasional.

Hala, Kartika dkk. 2016. Proyeksi Pertumbuhan Mobil Pribadi Roda Empat (Plat Hitam) Kota Manado Menggunakan Persamaan Diferensial Model Pertumbuhan Populasi Kontinu (Model Logistik). $J d C, 5$ (2), p.81.

Indraswari, Risa Ruri dan Risni Julaeni Yuhan. 2017. FAKTOR-FAKTOR YANG MEMPENGARUHI PENUNDAAN KELAHIRAN ANAK PERTAMA DI WILAYAH PERDESAAN INDONESIA: ANALISIS DATA SDKI 2012. Jurnal Kependudukan Indonesia, 12 (1),p. 1.

Iswanto, Ripno Juli. 2012. PEMODELAN MATEMATIKA: Aplikasi dan
Terapannya. Yogyakarta: Graha Ilmu.

Keuangan, Direktorat Jenderal Kementrian. 2015. Kajian Kependudukan.

Kurniawan, Arief. 2017. APLIKASI PERSAMAAN DIFERENSIAL BIASA MODEL EKSPONENSIAL DAN LOGISTIK PADA PERTUMBUHAN PENDUDUK KOTA SURABAYA. MUST: Journal of Mathematics Education, Science and Technology, 2 (1), p.139.

Nuraini dkk. 2018. APLIKASI PERSAMAAN DIFERENSIAL MODEL POPULASI EKSPONENSIAL DALAM ESTIMASI PENDUDUK DI KOTA BANDAR LAMPUNG. Prosiding: Seminar Nasional Matematika dan Pendidikan Matematika UIN Raden Intan Lampung,p. 402.

Statistik, B.P. 2019. Kota Balikpapan dalam angka 2019. Balikpapan: BPS Kota Balikpapan.

Sulaiman, Herri dan Dian Permana Putri. 2016. KAJIAN MODEL MATEMATIKA EKSPONENSIAL DAN LOGISTIK DENGAN CONTOH APLIKASINYA PADA PERTUMBUHAN POPULASI BAKTERI PANTOEA AGGLOMERANSDI MEDIUM LURIA BERTANI CAIR SISTEM BATCH CULTURE. Prosiding Seminar Nasional Matematika dan Pendidikan Matematika, p. 689690. 
Ndii, Meksianis Zadrak, 2018. Pemodelan Matematika Dinamika Populasi Dan Penyebaran Penyakit: Teori, Aplikasi Dan Numerik. Deepublish (CV. Budi Utama). 